\title{
ICT Prognoses for Easing Water Scarcity \& Its Energy Efficient Management: An Overview
}

\author{
Dr. Murari Lal Gaur ${ }^{1}$ \\ Professor (Soil \& Water Engineering), Department of Meteorology \& Agril Engineering, B A College of Agriculture, \\ Anand Agricultural University, Anand, Gujarat-389310 India ${ }^{1}$
}

\begin{abstract}
Water needs energy, energy needs water but human development needs both. Their intricate connectivity and dependencies revolve around many elemental issues. Present paper is focused towards deliberating updated overview on prospects of Information and Communication Technology (ICT) applications in water sector, seeing industrial, environmental, agricultural, municipal, domestic, recreational water utility segments. Portrayal of water communities, their existing challenges/risks, budding facets \& applicability of ICTs (gadgets, information systems, big-data, models, smart water \& energy systems) are deliberated with recently reviewed research results. Useful blend of information is offered on possible ICT amalgamations in water sector for transmuting ill water-systems into smart-water-systems, by achieving higher water productivities. Updated ICT oriented review is provided by uniting key challenges/risks of water applicability segments like transmission losses, leakage detections, energy reduction/recoveries in handling water, integrated water resource management for diverse stakeholders, climate-change, environment, irrigation, rainwater, water-quality, and sanitary aspects. Global initiatives (programs, consortiums, projects, collaborations) on ICTs in water sector are reviewed offering salient potential and forecasts of futuristic ICT based applications in such water segments. Pertinent food for thought is provided to pave road for smarter water management.
\end{abstract}

Keywords: Water-Security, ICT, Irrigation, Rainwater, Leakage-Control, Efficiency.

\section{INTRODUCTION}

Water is a prime entity on globe, as two thirds of earth's surface and $75 \%$ of human body comprise it. Availability of clean \& reliable fresh water is a fundamental global challenge, as only 3\% water is fresh. About 1.1 billion people worldwide lack access to water, while 2.7 billion find water scarce for at least a month in year (Helmbrecht et al. 2016). Between a rapidly growing population and shifting climate; water-based stress/risks are further escalating. About $85 \%$ world population still lives in driest part of earth, where around 748 million people do not have access to proper drinking water source (or even sanitation), making 'water security' a grave-fear. United Nations (UN) defines water security as the capacity of a population to safeguard sustainable access to adequate quantities of acceptable quality water for sustaining livelihoods, human well-being, and socio-economic development, for ensuring protection against water-borne pollution and water related disasters, and for preserving ecosystems in a climate of peace $\&$ political stability. Water insecurity remains equally vulnerable in energy \& industrial sectors, as global industrial water demand (only for manufacturing) is expected to increase by $400 \%$ between 2000 and 2050 (WWAP, 2015). More than 90\% global power generation remains water intense, which will be further intensive by 2035 , to meet projected hikes in water \& energy consumption being $50 \& 85 \%$ respectively. There exist huge stakeholders dealing with water, which remains most sensitive $\&$ decisive input for food, manufacturing, and energy systems.

Being a prime and most sensitive natural resource, the effectual management of water remains an extremely tedious and multifaceted task. Most of the managers, researchers, planners, users, and wide stakeholders in water sector faces glitches in regards to accurate and timely measured real data on water demands \& supplies at varied scales of time and space. It altogether needs a comprehensive set of system where consistent accurate measurements remains a crucial requirement. In managerial context, there remains a very famous saying that "You can't manage what you can't measure". Such measurements are never easy and feasible, as water sector comprehends a wide range of communities and stakeholders to deal various utility segments (irrigation, house hold water supplies, environmental water supplies, rainwater, surface water, soil water, ground water, river/stream flows, sea water, crop water, water quality aspects, atmospheric water, municipal water, health \& sanitation, and other social needs). Measuring, analyzing and managing water during its storages, supplies, utilities and backflows requires enormous efforts in terms of manpower, machine/equipments, money and other materialistic ingredients. All such constituents are often needed at varied nodes in space-time domain and under a real natural system where even assessing (if not measuring) too remains toughest task for water managers; making them totally handicap to harness the advantages of growing hydrologic or hydraulic 
Vol. 8, Issue 1, January 2019

modelling tools/techniques. At this junction, ICT has emerged as a versatile opportunity to bridge this gap and making water management easier with diluted level of water scarcity. Big-data, smart ICT gadgets, advanced models/information systems, and other innovative concepts are reinforced in this writeup for visualizing futuristic ICT potential in water sector making integrated water management an achievable reality at grassroot level under real time water resources systems at finer scales (temporal \& spatial).

\section{(A) Water Community \& Stakeholders}

There remain enormous stakeholders in water sector who are dealing/acting at different nodes of water cycle, to avail gainful opportunities out of it. Since each living or non-living element on earth has direct or indirect relevance with water; the water community becomes a large assemblage having clusters of, (i) people (farmers, industrialists, urban/rural population, researchers, businessmen, service-providers, policy-planners, entrepreneurs, water-users, watermanagers, water-providers, subject-experts), (ii) natural systems (watersheds, commands, rivers, canals, wells, aquifers, reservoirs, weather), (iii) manmade systems (drinking water supply lines/networks, waste-water systems, hydro-electric plants, energy generation plants), (iv) water utility segments (crops, irrigation, drainage, rainwater harvesting/recycling, industrial, domestic, environmental, livestock, recreational, conservation needs), (v) habitats (urban, rural, agrarian, non-agrarian), (vi) user groups (villages, cities, self-help groups), (vii) organizations (governmental, private, local, regional, national, global), and (viii) cross-sectoral enterprises (energy, environment, IT \& ICT, Societies). Above described cross-cutting nature of water has evolved an increased awareness amongst international, regional and local stakeholders, giving birth to a plethora of water related challenges/risks with them. Rivers use to be the life line of human and livestock community. Evolving \& applying ICT based interventions seems to be an effectual opportunity to deal with environmental degradation of water in such rivers/streams (Gaur, 2018).

\section{(B) Primary Challenges for Water Stakeholders}

Such challenges can be branded in varietal ways, reliant upon predominant fabric of water availability/utilities. Five nucleus groups might be articulated as 'over-allocated water', 'unreliable water supply', 'deteriorated water quality', 'high damages of floods \& droughts', and degraded eco-systems'. Once an active ICT integration is made, not only above cited prime action areas but many additional contests (given below) too can be connected/resolved,

- Water security \& risks in terms of water-based shortage, pollution, erosion \& floods. Nearly $80 \%$ world's population extremely sensitive to this regard.

- Huge water losses (quantitative/qualitative) occurred during storage, distribution \& applications via pipes/channels/canals/reservoirs/aquifers/sea/atmosphere.

- $\quad$ Energy recovery under prevailing water-energy-food Nexus to regulate, optimize, \& recover energy use in water sector specifically pumping operations.

- $\quad$ Environment \& climate change coercions, natural disasters/stresses on water resources.

- $\quad$ Water quality deteriorations (surface, soil, underground) with ample data.

- $\quad$ Deficits in regional data $\&$ predictive models

- Dealing wastewater \& sanitation issues, as world's $80 \%$ wastewater is discharged back into rivers/streams/oceans without proper treatment.

- $\quad$ Functional deficits in water governance \& policy

- $\quad$ Adding smart elements to meet technological \& policy level challenges

- Other long-term uncertainties (investor's growth, technological upgradations, rising energy cost, population, skills, affordability, aging of assets, changing demands)

By now ICTs are well recognized for their positive role to tackle climate-based risks by early warning, dematerialization of work by e-services, network development, hub for communication \& information, indigenous knowledge documentation, knowledge mapping, and capacity building of water stakeholders. More recently the IndoCanadian effort (IC-IMPACTS) has set a high stage for ICTs in water quality sector. EU group (EurEau) having 29 European-countries, 32 national-members, \& 70000 water-service providers, pushed top 10 water challenges for next 10 years as follows,

1. Protecting water as a vulnerable resource

2. Building effective strategy to diminish presence of micropollutants in environment

3. Increasing public understanding of water sector

4. Responding to growing impact of climate change on water

5. Giving water its value in the circular economy

6. Increasing resource efficiency in the water sector

7. Fostering sustainable economic growth and creating jobs

8. Setting the right price for water services

9. Managing long term assets in a fast-changing environment

10. Reinforcing the resilience of water services to security risks 


\section{International Journal of Advanced Research in Computer and Communication Engineering}

Vol. 8, Issue 1, January 2019

Present paper offers some food for thought for upbringing the ICT based applications in challenging era of water sector and its sub sectors. Some of the renowned efforts at global, national and local scales are traversed and reported herein, which could pave a path for futuristic smarter management and conservation of water resources by being inclusive, integrative, and demand $\&$ data driven. It could be of immense utilities for engineers, managers, researchers, scholars, policy planners, users, providers, and many stakeholders who so ever are involved in water sector at various levels.

\section{METHODOLOGY}

Findings are based upon search \& analysis of related literature, secondary information, data and thoughts. Customary quality search procedures were adopted by reading \& surfing updated information on key aspects of water related challenges and diverse ICTs for solving them by obeying interoperability \& connectivity perspectives. It included combining of existing literature reviews, its multiple screening, creating optional frameworks, seeking \& filtering key issues and then deriving, dividing, and discussing the matrix of gaps, constraints, opportunities, prospects, and deliverables. Many ongoing efforts, programs, success stories and innovations for ICT appliance in water/energy/environmental sectors were traversed, to pursue projections and conduct diagnosis of likely cross-sectored integrations of digital proficiency. Gathering review of literatures included both published/unpublished sources of global information (journals, books, bulletins, official reports, project documents). It also incorporates inherent knowledge and massive on-ground exposure of author himself, while dealing/consulting wider range of water stakeholders/technocrats (persons \& institutions), field visits/exposures on many projects (water resources, watersheds, irrigation, drainage, command areas, rainwater harvesting, land use influences, water \& soil erosions, conservation, NRM), and plentiful exposures in scientific meets \& consortia. Reviewed stuff was transformed into broader standpoints, keeping focus towards variety of water stakeholders. Efforts are made to accommodate most recent publications and information grids. It included primary \& secondary data/information from many reliable sources towards conceptual, quantitative, qualitative, survey findings, case studies and other factual/data-based evidences, policy information, published meta-data and its analyses. Criteria for assortment of information sources were ordered, based upon their proximity to water, energy, \& environmental sectors.

\section{RESULTS AND DISCUSSION}

\section{(A) Perceived ICT Approaches \& Potentials to Deal Water Challenges}

ICT indeed is an umbrella term encompassing rapidly emerging products \& systems like; computers, software, networking, telecommunications, internet, programming, information systems, high speed data processing, internet protocols, remote sensing, and many others. It has big pivotal role in monitoring, mitigation and adaptation of above challenges, by productive utilization of technologies like; Geographical Information System (GIS), Wireless Sensor Networks (WSN), Mobile Technology (MT), Web-based applications, Satellite Technology, Remote Sensing (RS), Artificial Intelligence (AI). ICTs offers, quicker access to real-time water information, creation of common-information bases, greater interoperability, easy management of equipments/processes/water-governance, water-system components $\&$ decision supports (Akhmouch and Clavreul 2017). It is evolving as a big choice to get its entry into a water sector via four major gates; namely water utilities, water technologies, water segments, and varied societal needs, with specified constituents/actors cited in Fig.1. ICTs could provide numerous enables in water sector by judicious utilization of its designated fields like; high-speed-network, mobile-communication, security, sensor, device-network, high-speedcomputing, large-capacity, high-speed-storage, large-capacity information analysis, cognition, human-machineinterfaces, imaging \& sound technology, information-message-device, electronic-measurement etc.

\section{Growing ICT based Infrastructure: Capable to Deal Water Challenges}

As per recent statistics in developed countries $94 \%$ of young people uses internet compared with $67 \%$ in developing countries and only 30\% in Least Developed Countries (LDCs). Out of the 830 million young people who are online, 320 million (39\%) are in China \& India. In LDCs, 35\% individuals using the internet are young people aged 15-24, compared with 13\% in developed countries and 23\% globally (ICT, 2017). More households in developing countries own a mobile phone than have access to electricity or clean water, and nearly $70 \%$ of the bottom fifth of the population in developing countries own a mobile phone. The number of internet users has more than tripled in a decade from 1 billion in 2005 to an estimated 3.2 billion at the end of 2015 (Hilbert, 2015). Sectors like fiber, cables, big data \& systems, transmission technologies, software, smart gadgets, high speed web services, artificial intelligence, machine to machine and machine to human interfaces, robotics, social media tools, space-based GIS \& RS, and high-speed information highways are also marching ahead (Fig. 1). The proportion of fiber broadband subscriptions per 100 inhabitants in developed countries is twice as high as in developing countries, and ten times higher than in LDCs. The share of fiber in total fixed-broadband subscriptions is highest in Asia \& Pacific. International internet bandwidth grew 


\section{International Journal of Advanced Research in Computer and Communication Engineering}

Vol. 8, Issue 1, January 2019

worldwide by $32 \%$ between 2015 and 2016, facilitating 70\% of world's youth being online. Smart consumer dashboards for Web-based analytics, 2-way smart meters, 2-way wireless communications are certain brilliant options to bring better command \& control on functionality of existing water meters/valves; ensuring demand-driven water allocations /applications.

\section{Managing Water Systems}

Water community deals with enormous systems (weather system, urban water supply system, rural water supply system, wastewater utility \& treatment system, hydrological systems, integrated water management system (IWRM), surface water system, ground water system, sea water system, water quality systems, cascaded water systems, watershed system, command area system, canal system, river system, irrigation system, reservoirs systems, well systems, aquifer systems, wastewater system, environment system, rainwater harvesting system, recreational water system, soil water systems, hydro-geological system). Researchers (Mizuki et al. 2012) have demonstrated the utilities of smart technologies in water resource system monitoring sensitive sectors of water utilities for urban (drinking, sanitation, health) \& rural (irrigation, recharging) domains.

\section{(B) Ongoing Global Initiatives on ICT Applications for Water}

Globally there exists enormous ongoing ICT based projects, consortiums, platforms on smart water management. United States (US) and European Commission (EU) based efforts are leading ones to attain common goal of increased water use efficiency (WUE). EU based 'ICT4Water' (water cluster platform having 10 FP7 projects) has demonstrated variety of ICT based solutions. Smart 2020, dealt with total water facets (quality \& quantity, food \& environment) targeting $15 \%$ reductions (by 2020) in global emissions by enabling energy efficiency in water sector. Connecting people $\&$ connecting things is another fabulous effort with projected 50 billion machine-to-machine connections by 2020. GeSI, (2015) envisages benefits of ICTs as $30 \%$ increased agricultural crop yields, saving 300 trillion litres of water \& 25 billion barrels of oil per year, by connecting 2.5 billion unconnected people to ICT based services, by 2030 . 'Interreg Europe' is another giant move to help local governments across Europe for developing/delivering better water policy/smart water solutions via 120 projects in 4 major groups viz. research \& innovation, SME competitiveness, low carbon economy, environment \& resource efficiencies. There exists plethora of such smart moves world has initiated, for paving important path to integrate ICTs in water sector.

\section{(C) Proven Potential \& Prospects of ICTs: Reviewed Literature}

The description of findings from such a big water \& ICT based knowledge sphere evolved variety of challenges that remains crucial for making penetration of ICT based interventions in various nodes of natural water cycle. Details in regards to such crucial challenges are well illustrated in part-b of Fig. 1, by encompassing 6 decisive portfolios namely leakage/loss, water consumption, water awareness, energy consumption, water conservation, and tailor-made technological mapping. Results have clearly established that there exist positive \& highly valuable impacts of ICT applications to resolve majority of beset water challenges. Some are described below,

\section{Easing Water Security \& Risks}

ICTs have large potential to cope up with water security, which used to be an enduring struggle to handle water access and shocks. According to UN estimates, $85 \%$ of world's population lives in most arid regions of the planet; 783 million people do not have access to clean water; almost 2.5 billion do not have access to adequate sanitation; and 6 to 8 million people die annually from the consequences of water-related disasters/diseases (CIMUN, 2013). Problems are particularly acute in Asia (only $3920 \mathrm{~m} 3 /$ person/year freshwater) than any other continent.

\section{Water Informatics \& Predictions}

Enabling accurate/adequate water-data is an important need to secure desired level of water efficiencies \& demand management. The world is witnessing an unprecedented explosion of data. Digital data overtook analogue around 1998, and in 2013 amounted to 46 billion trillion bytes. That's equal to about 400 trillion printed copies of a 100-page report, which when slanted would reach from Earth to well beyond Pluto. World's big data capacity can be understood in terms of world's storage capacity \& telecommunication capacity to access this storage i.e. cloud. (Hilbert, 2015). Rewards of such big-data are proved priceless for water-based modelling\& simulations (Gaur \& Kumar 2018). A wide spectrum of real-time data-based monitoring technologies (Kanwar et al. 2010) are always found worthy to brand water informatics as an important element for water community. It facilitates dealings across multiple arenas like water contamination detection, geodatabase integrations, compatibility of data base/shape files, specified hydraulic software concerts, extended period simulations (EPS), water quality analysis (WQA), graphical user interface (GUI), and integrated GIS. integration of GIS with advanced models, yielding decision support systems (DSS) for smart water planning \& management via information-theoretic tools (neural networks, fuzzy set) are some other potential areas. 
Vol. 8, Issue 1, January 2019

\section{Enhancing Energy Efficiency}

Water industry at global level is heavy consumer of energy, triggering a big concern towards not only direct costs, but ancillary environmental damages too (Helmbrecht et al., 2016). Integrating ICTs will certainly deliver multiple positive impacts, as most of the water resources systems have lower energy efficiency. Transporting water remains one of the most energy intensive processes, where selection of pump can do a wonder (but it seldom considered seriously). Lima et al (2017) have reported interesting ICT based innovations where location \& selection of pumps as turbine can greatly inspire functional utilities of pressure releasing valves in a water system. Claiming performance of a pump is equivalent to claiming fuel efficiency of a vehicle. It is well established that mere scheduling of pumps can utterly regulate energy utilization in a water supply system.

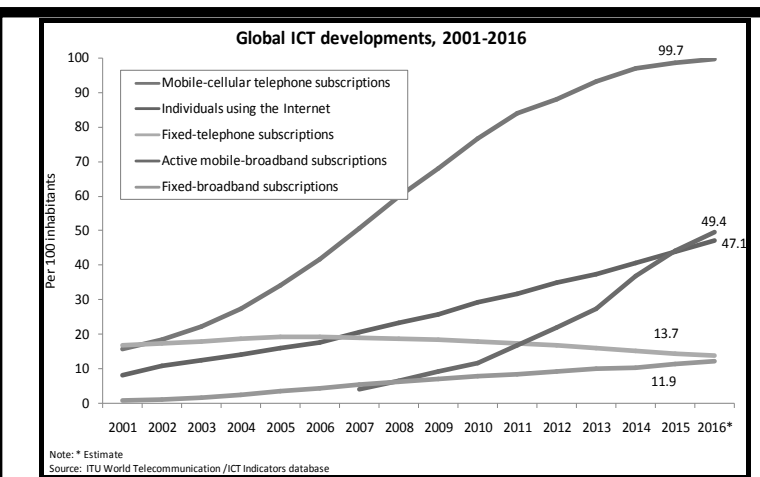

Global ICT development (2001-2016)

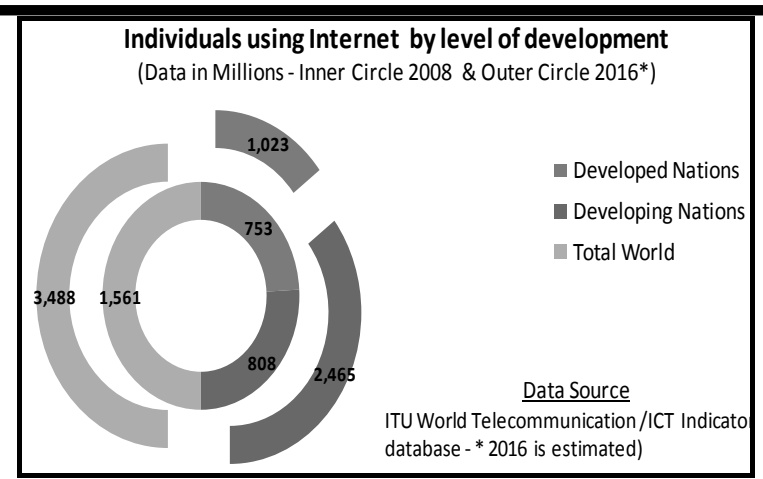

Individuals Using Internet (2008-2016)

( a ) Key ICT indicators with sharp expanding patterns at global/regional scale (Data Source : http://www.itu.int/en/ITU-D/Statistics)

\section{Reduction of Leakages/Losses}

(Leak detection/localization, Network modeling, Leak control, Leak identification)

\section{Reduction of Water Consumption}

(Promoting Re-use/Cascaded use, Water distribution network monitoring, Awareness \& behaviour of water users, Controlling transmissin losses)

Promoting User Awareness/Behaviour (Adopting large no. of sensors for demonstrating real time measurements, Adopting low power sensors \& energy harvesting, contextual information, analysis/pattern recognitions of user's behaviour, digital/simulated water awareness messages via. society, relegeous guides, psychologists)

\section{Reducing Energy Consumtion in Water}

(Energy recovery, Timely/Accurate forecast of water demands \& management, recovery from water transmission/application volumes, Productive wastewater treatment, rain water harvestng and their effective reuse/recycling

Promoting Conservation by Reductions in
Peak Consumptions of Water \& Energy
(Drinking/Domestic, Irrigation, Industrial ,
environemntal,Stormwater, Riverwater,
Groundwater, Canalwater, Aquifer recharges/
discharges,Reservoir storages/releases etc.)

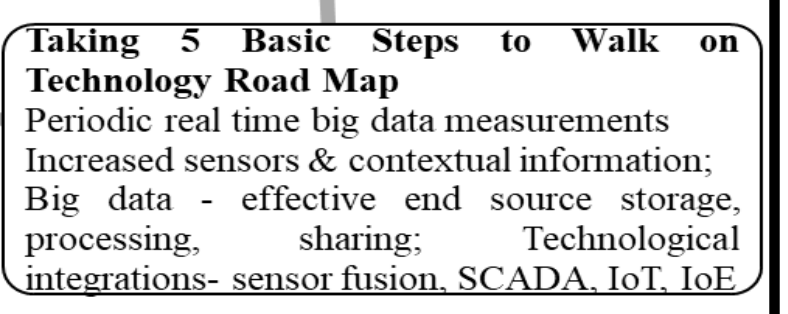

( b ) Crucial Challenges

Fig. 1 Growing ICT Setup with high prospects to meet key challenges of water sector

\section{Achieving Effectual Irrigation Water Utilities}

Owing to smart methods \& management, there have been tremendous advancements in irrigation sector to offer better water use productivities. ICTs have proven their high-level standing utilities for transforming prevailing irrigation systems into smart irrigation systems. Considering anticipated $30 \%$ increase of world population (8 billion people with improved living standards) by 2025, various basic models of food demand versus irrigation water demand are globally 


\section{International Journal of Advanced Research in Computer and Communication Engineering}

Vol. 8, Issue 1, January 2019

saying that that simultaneous water demands for irrigation would increase by $8-10 \%$ only (Ali, 2016). Such estimations are just based on just empirical guestimates. For all such qualms, it is the non-existence of proper data/information that pays huge role. ICTs are evolving as strong keys to bridge such gaps, once properlydiffused.

\section{Improvement of Irrigation Performances}

Agriculture is big-water consumer, but putting ICTs together with crop water schedules, is always found useful to adjust water consumption via. effective monitoring and environmental conservation of supplied water (Zhu et al., 2018). Unlike traditional water application methods, irrigation technology is considerably amended having massive reservoirs \& networks of canals to satisfy gravity irrigation systems, manually \& mechanically moved sprinkler systems, variety of innovative low-flow systems (micro irrigation, sprinklers, center pivotal, sub-surface irrigation, deficit irrigation) and other smarter ways of rainfall harvesting/recycling for life saving irrigations. Even then the due water use productivity remains far below the needs in majority of areas. It is just because of deficiency in water managerial front $\&$ irrigation information aspects. There are no better options than ICTs to overcome such hurdle. There exists overabundance of research on this aspect, however some of them (Zhu et al., 2018, Ali, 2016) have well corroborated advanced irrigation methods/approaches by deploying ICT based tools/approaches even using broadband satellite networks in rural areas. Replacement of electronic microcontroller card by a programmable logic controller with Ethernet modules further simplify water applications fit to crop situations.

\section{Achieving Higher Water Use Efficiencies \& Productivities}

The competition for accessible freshwater supplies needs a paradigmatic shift from maximizing productivity per unit of land area to maximizing productivity per unit of water consumed. ICTs are found extremely useful in attaining significant hikes in water application efficiencies, water distribution efficiencies, WUEs (Zhu et al., 2018). Flexibility in managing the rate, frequency, and duration of water supplies to attain best possible WUE \& productivity is broadly emphasized by researchers, which is possible only when use of ICTs is ensured. On dry lands it takes one liter of water to produce one kilocalorie of food. This means that each person consumes 3000-4000 liters of water, just while eating. The vast R\&D experience on dry lands (ICARDA, 2017) tells us that it is possible to produce more with less provided the correct application of precise expertise and know-how is made sure; and water cost is taken care. Rickards real water cost index (WCI) is a popular benchmark (IBM, 2013). Moreover, ICT has great potential role to narrow down the weighty disparity in WCI across different locations and time frame. Local WCI values are often computed by using below given standard relationship.

\section{Achieving Effectual Domestic Water Utilities}

For domestic sector, water losses during distributions/ applications are major concerns. Leaks are never good for survival of a system, whether it's a leaky boat or a leaky pipe system. As per EU based estimations about 20 to $40 \%$ of water is often wasted, mostly due to 'leakage' and "over-use". It gives two-fold problem which require two specific efforts, one for detecting \& tackling water leakages and other one to treat \& re-use wastewater. An effective set of implementation measures is being evolved by global experts via countless efforts, which needs replications in its downscaled configurations for higher number of locations \& time frames. Even one of the biggest water company in England namely 'Thames Water' is found to be the 'leakiest', with 20500 liters escaping every day per kilometer of main equating to 171 liters per property per day. Similar is the situation in many parts of the world, which inevitably demands for smart solutions to detect $\&$ correct the situations. Many researchers have analyzed leakage detection issue by adopting advanced approach, where a time domain reflectometry (TDR) based system for localization of such leaks.

\section{Technologies for Locating Water Loss Points/Pipes}

Developing a cost-effective reliable pipeline leak detection system remains in big demand, which was attempted to resolve by Nasir et al. (2014) and Sadeghioon et al. (2014) having smart detections with digitally controlled elements. Researchers have shared their positive results for operational utilities of smart metering, smart meters sensors, and wireless sensor networks for leakage detections. Preliminary kind of cyber centric and robotics-based pipeline monitoring is also attempted adopting acoustic setups promoting wavelet $\&$ neural network concept. Other works unites sensors to automatically locate leakages and sometime applying smarter approaches like of 'negative pressure wave method propagation' yielding smarter DSS.

\section{Governing Water Storage Losses}

Parcels of water (e.g. ponds, reservoirs, lakes, small water pools, aquifers, wells) stored on surface or below surface of earth, where digital technologies have high prospects for detecting \& localizing conveyance losses/leaks by preemotively identifying such 'hotspots' inside the water storage or open conveyance system, using ICTs. Important R\&D results (Savic et al., 2014) have well established the worth, usefulness \& interconnectivities among smarter adaptation of water meters, sensors, pressure controls, energy regulations, and other clever data. 


\section{International Journal of Advanced Research in Computer and Communication Engineering}

Vol. 8, Issue 1, January 2019

\section{Achieving Effectual Industrial \& Environmental Water Utilities}

Under predominant 'climate \& environmental settings', making smarter use of industry's resources is feasible, only if we minimize the volume of water used in routine manufacturing \& production processes. Reviewed literature exposed many associated solutions for securing/protecting adverse water impacts in such productions, which includes supply \& treatment, conveyance, and management of wastewater. Technologically advanced countries (Europe, USA, Korea) are well fostering creative industries, to revitalize their manufacturing sector on these fronts. Such 'creative industries' have become a driver of what has been termed the fourth industrial revolution, which is bringing concepts like Internet of Things (IoT) \& Internet of Services (IoS) to the industry (Gaur 2016). Benchmarking and bench learning tools are permitted as widespread options to improve energy efficiency in industrial water processes. Innovative ICT applications through web tools like Energy Management Self-Assessment (EMSA) and creation of Energy Angels network are paving new ways, for gaining high standard energy performances. The 'EnergyWater' \& 'WssTP' projects under EU framework have shown efficacious results. Many large corporations such as Coca-Cola, Johnson \& Johnson and MillerCoors are employing water conservation programs with integrated ICTs to improve water use and reduce their industrial water demands. Coca-Cola, achieved its goal of replenishing amount of water used to produce company's beverages to communities \& nature in 2015. Additional water used in company's facilities/manufacturing process was treated and returned to communities \& nature, with an estimated $115 \%$ return (191.9 billion liters) of water used in its global sales volume (Wesley, 2017).

\section{Establishing Smart Water Systems}

Any advanced water systems inexorably includes many smart portfolios/elements to regulate dynamics \& utilities of water within the system with balanced inputs \& outputs. Being a necessity to achieve end goals it needs to be essentially comprise 3 core elements, (i) information for making full use of water data, (ii) integration of current ICT to maximize previous investments, and (iii) innovation for designing a flexible system to meet future challenges. The smartness of its major elements (ICTs, gadgets, approaches, data, decisions) remains the core strength of such water systems as globally evident. Mizuki et al. (2012) have narrated many such technological options to visualize a true smart irrigation system at micro level. It may further accommodate satellite-based measurements, internet-based disseminations using advanced data (Meteo data, Earth observation data, MODIS), cell phone data processing, sophisticated data processing, meteorological data processing, and many smart ICTs. Further 'eLEAF field look platform' too has demonstrated smarter versions having more advanced features like, interaction with data received by SMS, advisor functionality, adjusted design for slower connections, adapted parameter pack with flood/drought based data, and WUE .

\section{Water \& Energy Smart Grids}

It is emerging as another innovative approach to address water scarcity, promote efficient water use, update existing water infrastructure, improve water quality and reduce water related energy consumption (Brzozowski, 2011). It is always considered as an innovative technology suite, to include smart water meters, sensors, advances modelling, water mapping, smart irrigation, autonomous robots, and other technologies, that would work together to create a data-drive system for intelligent management of water resources. It offers utilities with real-time information on water consumption from consumer, commercial, industrial and agricultural domain.

\section{Creating Smart Society}

Societies remains the ultimate client for any technology. Ongoing concept of smart cities \& villages has very sensitive connectivity with water. Its numerous external factors (climate change, resource depletion, population growth, demographic changes, concentration of populations in cities) adequately stimulus people's lives with theatrically created water scarcity. Adoption of optimum ICTs having intelligent water systems remains foreseeable prerequisite (Mizuki et al. 2012). ICT enabled smart systems namely, membrane bio-reactor (MBR) \& MBR-RO system, water information \& control system, water supply management system, water distribution control system, low emission wastewater treatment control system, controlling water desalinization \& recycling systems are revolutionary realities. Globally renowned companies (Hitachi, IBM, ABB) are keeping highest alertness towards smart water distribution systems in any smart sustainable city (ABB, 2013), considering water as nucleus element. The smartness of any city can be better evaluated by the way the issues are solved rather than the shape of the existence of city.

\section{Futuristic Road Map}

The futuristic goals \& priorities for ICT- enabled water sector might be set as peak-period reduction of water \& energy distribution loads, savings in consumer water/energy, reducing Co2 emissions, and real-time testing \& validating of water systems \& water needs/supplies. Reviewed results have well established the fact that if these priorities are adhered, there can be made a saving of at least 15 to $20 \%$ in water. Moreover, smarter coordination and participatory involvement of varied water stakeholders remains a pre-requisite. Strong attention is needed towards 3 specific blocks 
Vol. 8, Issue 1, January 2019

(i) innovative demand management system, (ii) smart decision support system, and (iii) big data \& information management. To achieve these, it becomes inevitable to set and re-orient our location specific priorities, values and R\&D needs for overcoming barriers and creating higher opportunities of gains. While there exists, multiple challenges, there remains equal multitude of opportunities that can be reaped with the help of ICT. There are evidences where investing just $2 \%$ of a nation's GDP into key sectors of the economy (transportation, manufacturing, water, waste management) has revealed higher growth in GDP compared to a business-as-usual scenario can be produced within 5 to 10 years. The concept of smart water systems could be a big boon for water stakeholders, as evident from larger efforts and success examples encompassed in this paper. It could be tagged into 4 specific domains namely, smart logistics (hosting efficiencies in transport \& storage of water/wastewater), smart systems (cities, villages, catchments commands, rivers, canals, ponds, wells, pipes, channels, weather, water bodies as a largest driver for water \& energy use), smart grids (for reducing transmission/distribution losses through better monitoring of water \& energy grids and ICTs), and dematerialization (to dematerialize ongoing water systems/utilities by replacing physical objects/activities with ICT based electronic/virtual alternatives). Prime necessity for coming time or next generation water managers is always going to remain an inclusive \& intelligent understanding towards region specific architecture \& adaptation arena of ICTs within natural or manmade water resource systems. It inevitably requires smart concepts like interoperability, energy/power supplies, measurement frequencies, valued communications, software/modelling, sensors/high tech gadgets, water reuse and cascaded utilities of water.

\section{Innovations \& Strategic Breaks}

It needs a sharp shift from a 'culture of attention \& reaction' to a 'culture of preparation \& prevention', for managing water born disasters \& scarcities. Some futuristic R\&D aspects on ICTs may orbit around,

- Mitigating emerging water issues for community, global values, demand-supply chains, consumer trends, business practices

- $\quad$ Monitoring energy conservation aspects of water, environment, and society

- Low cost technologies for impact assessments of climate changes \& land use effects

- $\quad$ Adaptation of ICTs to generate effective platform for social messages at micro level

- $\quad$ Compiling \& sharing of local voices/traditional knowledge bits for water use alertness

- $\quad$ Research based strategies on ICT appliances for smart water systems

- $\quad$ Evolving base to facilitate good governance and DSS for water sector

\section{Evolving \& Adopting Smart Elements of ICT}

There have been vast trials and attempts to evolve effective gadgets, tools, techniques and other means of ICTs (Olsson, 2011). For water communities/stakeholders there exists bright scope for incorporating some of the relevant recently evolved options like IoT, IoS, Big Data, Cloud, SCADA, Telemetry, M2M Solutions, Artificial Intelligence, 5G, Connected vehicles, Multimedia Content \& Apps, Advanced Networks, Cybersecurity, Emergency Communications, Information Management Systems, Cloud Computing Configurations like infrastructure as a service (IaaS), platform as a service (PaaS), software as a service (SaaS) etc.

\section{Tackling Water Footprint of ICT}

More recently people are talking regarding water foot prints for ICT sector itself, because significant amounts of water are used in everything from chip fabrication to PC manufacture to data center operation. There are concerns being shared on web how the prominent IT companies/ventures (even Google) are using water to cool their data centers and other utilities across various manufacturing, managerial and routine operational activities. We might withdraw more water for the energy sector than for agriculture, but question arises to research and verify that how much this is linked to ICT, because data centres could be functioning as thirsty creatures just by energy they consume. To come over on such issues, more recently emerged concept of 'Green ICT' might be considered another futuristic intervention with sharpened integration of ICTs in water sector.

\section{Replicating Success Stories}

There are enormous successful ICT applications, which need to be utilized for learning lessons. Smart water metering projects in Europe \& North America, represents about 89 \% of global smart water market. The 'Digital Delta Initiative' in Netherlands is another successful cloud-based system having consulting capability to cut high cost of water management caring water quality \& extreme weather events and offering $15 \%$ reduced water management costs. 'Veolia Environment', a transnational company of France gave successful solutions to meet needs of municipal \& industrial water stakeholders, waste management, \& energy management. Italy too have evolved many success stories (e.g. IWRM for Tiber River Basin) adopting GIS \& web processing service (WPS) to improve remote management of water resources. 'MajiData' is becoming popular as an online database service developed in Kenya. ICeWATER a widespread EU project has delivered many success stories to establish many advantages of ICTs; like energy 


\section{International Journal of Advanced Research in Computer and Communication Engineering}

Vol. 8, Issue 1, January 2019

efficiencies in water supply systems, real-time monitoring of water supply/demand parameters, DSS based simulation/optimization models, and efficient operational strategies (pressure \& energy management, pump scheduling). Digital Yellow River Project of China is effective trial to manage frequent devastating floods for some deadliest disasters. Mobile phones are vastly being adopted for improved warnings on water based eventualities like cyclones, storm surges, droughts, floods etc. India too have marched ahead by offering success landings like Jal-Chitra (an ICT tool for water management in Indian arid zone is offering interactive water maps/pictures for local people), Neerjaal (ICT-enabled water resource management system is highly popular among communities in water scarce regions); NextDrop (mobile based information on local piped water deliveries). ComDev and COMMON-SenseNet are other success stories. Several big layers (IBM, Siemens, Schnieder, GE, ABB, Nalco, TaKaDu, i2O water), are now a day opting for new ventures/business for varied digital aspects of water. We need to learn lesions from here to facilitate deeper ICT penetrations.

\section{CONCLUSION}

Access to fresh water remains a basic human right and thus a decisive factor to govern overall health, wellbeing, livelihood, and business of any individual or society on this globe. The functional \& utility domain of water is involving many other sectors, hence managing and regulating water can never be a mere quantity \& quality. It involves other enormous lines of sight, which could be well attained by including powerful newer ICT tools to facilitate collection, storage, management, and display of water related data \& information followed by tailor made simulation models for better decision making and understanding of physical water system and their appropriate managerial/developmental actions. Value of any entity gets established only when some price is associated with it. Unfortunately, 'water' is still being taken as granted, without any such thought. Different sectors have their own concerns to look upon water utilized by them. In majority of cases there is no data to establish the water price. Accordingly, the bottom line for a true water cycle solution is collecting the right data at the right time, integrating it through the right communication system and applying the right analytics. To execute valid smart water cycle application, the effort must be founded on measuring accurate $\&$ timely data using better devices. Truly accurate data, when collected, communicated and analyzed properly, will ultimately: decrease costs, increase efficiency, grow potential revenue, optimize assets as used in water cycle process (industry, agriculture, pipes, channels, storages), reduce risks (water main breaks, contamination, public health hazards, floods, droughts), and enhance customer service \& consumer quality of life (cleanliness, reliability, water pressure). Over the last few years ICTs have shown deep impacts on society to radically influence the water-based economy. It has tremendous hidden potential capable enough to solve many complex issues of water sector at varied points of time and space. Majority of issues and challenges discussed in paper needs to be resolute in a holistic approach. The advanced digital technologies and data will certainly pave a path of success to transform all the extreme threats and challenges of water sector into some big opportunities. Though the results/discussions offered herein are not ever complete scenarios, but still this tiny portrayal may be evidenced as an important strength-full foundation brick for a big edifice of 'ICT based Water Community \& System'. More bricks and mortars are to be added upon, to change the prevailing perception of water stakeholders for ignoring water system needs being inclined towards water-based production rather water-based protection.

\section{REFERENCES}

[1]. ABB. 2013 Symphony Plus: The total automation solution for water and wastewater. http://www.abb.com/water (accessed 21 Jan 2018 )

[2]. Ali A. 2016. Effect of intelligent irrigation technique on water use efficiency for cucumber and pepper crops in New Salhia Area, Egyptian Journal of Soil Science,56(4), 761-773.

[3]. Akhmouch A., \&Clavreul D. 2017. Towards inclusive water governance: OECD evidence and key principles of stakeholder engagement in the water sector. In: Karar E. (eds) Freshwater Governance for the 21st Century. Global Issues in Water Policy, vol 6, 29-49. Springer, Cham

[4]. Brzozowski, C. 2011 The smart water grid: A new way to describe the relationship between technology, resource management and sustainable water infrastructures. Water Efficiency, 6(5), 10-23.

[5]. CIMUN .2013. UNDP Study Guide. http://www.cimun.in/pdf_files/UNDP-\%5BStudy-Guides\%5D.pdf (Accessed 21 Dec 2017).

[6]. GeSI. 2015. SMARTer2030-ICT Solutions for 21st Century Challenges. http://www.smarter2030.gesi.org/downloads/Full_report.pdf (accessed 02 Feb 2018)

[7]. Gaur S. 2018. An Updated Review on Quantitative and Qualitative Analysis of Water Pollution in West Flowing Tapi River of Gujarat, India. In: Singh V., Yadav S., Yadava R. (eds) Environmental Pollution. Water Science and Technology Library, vol 77. Springer, Singapore

[8]. Gaur M. L., \& Kumar S. 2018. Preliminary Investigations on Localized Rainfall Interception Losses Under Real Field Observations. In: Singh V., Yadav S., Yadava R. (eds) Hydrologic Modeling. Water Science and Technology Library, vol 81. Springer, Singapore.

[9]. Gaur, Murari Lal. 2016. Vision and Challenges for Clasping Factual Potential of "Internet of Things" towards Agricultural Wat er Management. In: Proc. International Conference on "Food, Water, Energy Nexus in Arena of Climate Change, Anand Agril University Anand Gujarat India during Oct. 2016.

[10]. Helmbrecht J., Maier M., Morillo E. M., Kuhlers D., \& Roth K. 2016. Improvement of the Water-Energy Nexus and the Environmental Performance of Water Supply Systems Using Smart ICT Solutions. Current World Environment, 11(3), 679-689.

[11]. Hilbert Martin. 2015. Quantifying the Data Deluge and the Data Drought. Background note for World Development Report.https://ssrn.com/abstract (accessed 20 Feb 2018).

[12]. ICARDA. 2017.Water Harvesting: bringing water to communities. http://www.icarda.org/tools/water-harvesting. (accessed Jan 31 2018)

[13]. IBM 2013. IBM Intelligent Water. In:. IBM Analytics-Solution Briefs: Infrastructure Services p1-8. https://public.dhe.ibm.com/common (1 Feb 2018) 
Vol. 8, Issue 1, January 2019

[14]. ICT. 2017. ICT Facts and Figures. http://www.itu.int/en/ITU-D/ (accessed 23 Jan 2017)

[15]. Kanwar Rahul, Narayan Ujjwal, \& Lakshmi Venkat. 2010. Web service based hydrologic data distribution system. Computers \& Geo-sciences. 36(7), 819-826.

[16]. Lima G. M., Edevar L., \& Bruno M. B. 2017. Selection and location of pumps as turbines substituting pressure reducing valves. Renewable Energy. 109, 392-405.

[17]. Mizuki Fumio., Mikawa Kazuhiro, and KurisuHiromitsu. 2012. Intelligent Water System for Smart Cities. Hitachi Review, 61(3), 147-151.

[18]. Nasir A., Hussain S. I., Soong Boon-Hee, \&Qaraqe Khalid. 2014. Energy Efficient Cooperation in Underlay RFID Cognitive Networks for Water Smart Home. Sensors, 14, 18353-18369.

[19]. Sadeghioon A. M., Metje N., Chapman D. N., \& Anthony C. J. 2014. Smart Pipes: Smart Wireless Sensor Networks for Leak Detection in Water Pipelines. J. Sens. Actuator Netw. 3(1), 64-78.

[20]. Savic D., Vamvakeridou-Lyroudia L., \&Kapelan Z. 2014. Smart Meters, Smart Water, Smart Societies: The iWIDGET Project, Procedia Engineering, 89, 1105-1112.

[21]. WWAP. 2015. Water for a Sustainable world - assessment based on survival analysis, UN world water development report - world water assessment programme, Water Resources Management, 25(14), 3729-3746.

[22]. Wesley Lobo .2017. 5 strategies to lower your company's water footprint. Water Technology magazine. 2018. Pub. Endeavor Business Media Birmingham https://www.watertechonline.com/ (Accessed 18.Feb 2018).

[23]. Zhu X. Y., ChikangaiseP,, Shi W. D,, Chen W. H., \& Yuan S. Q. 2018. Review of intelligent sprinkler irrigation technologies for remote autonomous system. International Journal of Agricultural \& Biological Engineering, 11(1), 23-30.

\section{BIOGRAPHY}

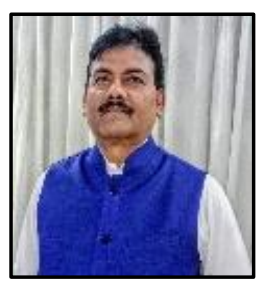

The author has more than 34 years multifarious experience in research, education and transfer of technology aspects of natural resources management, soil \& water conservation engineering, watershed planning and management, irrigation and drainage engineering, command area development \& management and many other portfolios of agricultural engineering sector. He obtained his $\mathrm{PhD}$ in the field of Hydrology from Indian Institute of Technology Roorkee and served for about 24 years holding various scientific positions at several National Research Institutions under Indian Council of Agricultural Research, New Delhi. Afterward he had been in agricultural education stream for last 10 years, holding positions of Professor, HOD, Principal, and also the Faculty Dean of Agricultural Engineering under his present organization i.e. Anand Agricultural University. He has more than 50 prime publications in international \& national journals and books with equal number of other publications in diverse fields of watershed, hydrology, grasslands, forest lands, rainfall runoff modeling, GIS\&RS, rainwater harvesting, soil erosion \& sedimentation, wasteland development and climate change/agrometeorological aspects. He has more than 6 national appreciations (medals, awards, fellowships) and several other professional recognitions in his name. 